\title{
RFID based protection to newborns in the hospitals
}

\author{
Ahmed Qasim Abd Alhasan ${ }^{1}$, Syed Imtiyaz Hassan ${ }^{2}$ \\ ${ }^{I}$ (Department Of Computer Science / JAMIA HAMDARD, HAMDARD UNIVERSITY, India) \\ ${ }_{2}^{2}$ (Department Of Computer Science / JAMIA HAMDARD, HAMDARD UNIVERSITY, India)
}

\begin{abstract}
Many hospitals, these days depend on the Information Technology (IT) to achieve perfection in the health services and operation management. The said dependency is because of the ability of emerging technologies to solve the problem of different nature. One of the problems where applicability of the IT can produce revolutionary solution is the cradle kidnapping and swapping of newborns in hospitals. It can be achieved with proper usage of the Radio frequency identification (RFID) technology. The present work is an attempt to explore and then utilize RFID technology in healthcare to protect the newborns in the hospitals from kidnapping and swapping. Apart from implementing a sample case the present work also characterize the RFID system in terms of the different elements that it constitutes (readers, tags, software, and security programs).
\end{abstract}

Keywords: RFID, Hospital management, Cradle Swapping, Cradle kidnapping

\section{INTRODUCTION}

The use of Radio frequency identification (RFID) technology for identity of object, tracking of object, location identification and security of resource is well known. The said capabilities of RFID is can also be used in the health care industry. The use of RFID along with IT can directly solve the various issues that are currently faced by health care organizations while also helping to drive down costs [1].

\section{RFID SYSTEM}

An RFID system is always made up of two components [2] [7]:

1. The transponder: is attached with the object to be identified

2. The interrogator (or reader): used to read or write/read device

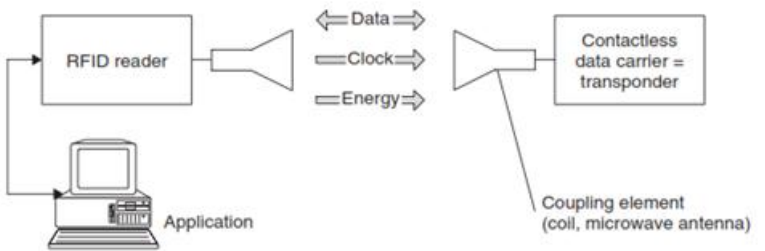

Figure 1: Components of RFID system (adopted from [2])

Some of the features of RFID system may be:

- Warranty at work: RFID tags proved their ability to work with the environment that is subject to repeated physical and climatic cycles. RFID has effective read capabilities in extreme situations, also.

- Flexibility in dealing: RFID tags can be combined with healthcare applications. It can be used to several purposes where data are to be read without manual keying and without physical contact.

- Sensitivity from manipulating: RFID tags can be designed as it can be sensitive from a manipulation. As soon as someone wants to manipulate and update information an alarm can inform if placed with alarming system.

\section{USE Of RFID In ChILD PRotection In Hospital}

The public hospitals of developing countries are generally very crowded and hence are more prone to cradle swapping and cradle kidnapping. Even in developed countries like United States cradle swapping is one of the major concern. Every year around 1, 00,000 to 5, 00,000 newborns in United States are exchanged (swapped) by mistake, or one out of every eight babies born in American hospitals sent home with the wrong parents [3]. According to a study [4], out of 34 newborns that are admitted to a neonatal intensive care unit there are $50 \%$ chances of incorrect newborns identification only in a single day.

In real applications, the biometrics traits that are commonly used in different authentication systems are the face, fingerprint, hand geometry, palm print, signature, iris, voice, etc. [5]. But most of these practical biometric systems are developed for adults only and may not be a solution with newborns. RFID system is very effective in protection of the newborn in such hospitals. A special designed RFID tags attached with baby and 
his mother along with tag reader and automated system can manage the above issues. The key advantages of such systems for health-care delivery may include [6]:

- Precise identification of objects without any physical contact or line of sight.

- Sensors can also be integrated into RFID tags to record temperature or to spot positioning.

- Data stored inside RFID tags can be encrypted, customized and made available as per need.

- Tags are recyclable and can be made complex to imitation.

- As a special device is required to read RFID tags and may not be human readable format increases.

\section{RESEARCH METHODOLOGY}

This research is an attempt to protect the newborns in the hospitals using the RFID technology. A wristband active tag can be used for this purpose. The wristband may be tied to child and his mother and the authorized hospital staff. RFID readers in newborn hall may be used to read the signals and keep tracking on the activities of children, mothers and authorized staff members present in the hall. With proper automation it will be impossible to swapping and kidnapping of newborns.

\section{PROPOSED WORK}

The proposed solution has used active RFID tags, RFID readers for (short and long distance), C\# .Net framework 2010 and SQL Server 2008.
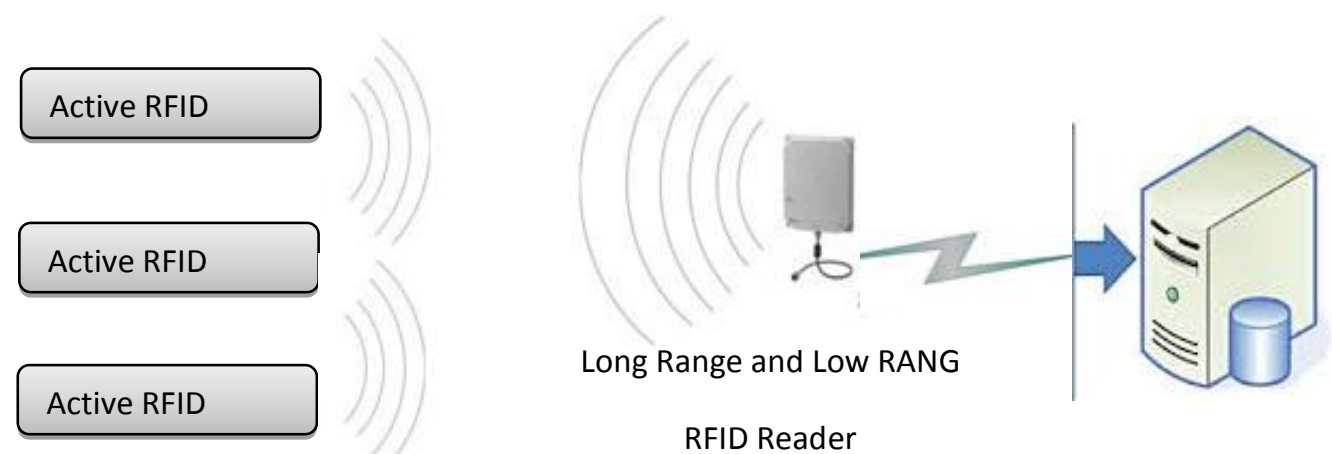

Figure 2: RFID System block diagram

As seen in block diagram there are two RFID readers one with long range 15 to $25 \mathrm{~m}$ (approx.) which covers the length of the room where children's are kept and the other is low range of 1.5 to $2 \mathrm{~m}$ (approx.) installed near of the door to check the identity of the authorize of personnel .

The present setup has used active RFID tags that transmit their identity (ID) to the installed readers. The system keep track of the ID's broadcasted by the tags and store the necessary information in the database to keep track on the activities of children, mother and staff members present in the hall .

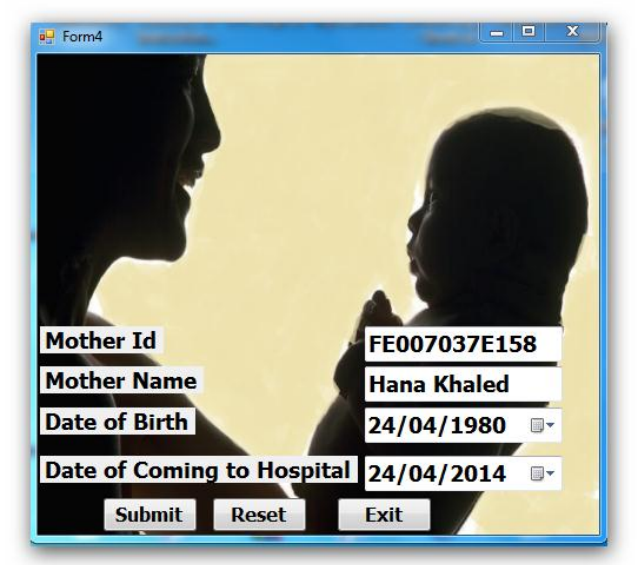

Figure 3: The mother Information Registration interface

To authenticate a mother for a child, both have been assigned a wristband with same ID. At the time of issuance, the necessary information related to mother and child has to be stored in the database (refer figure 3 \& figure 4) along with the IDs. 


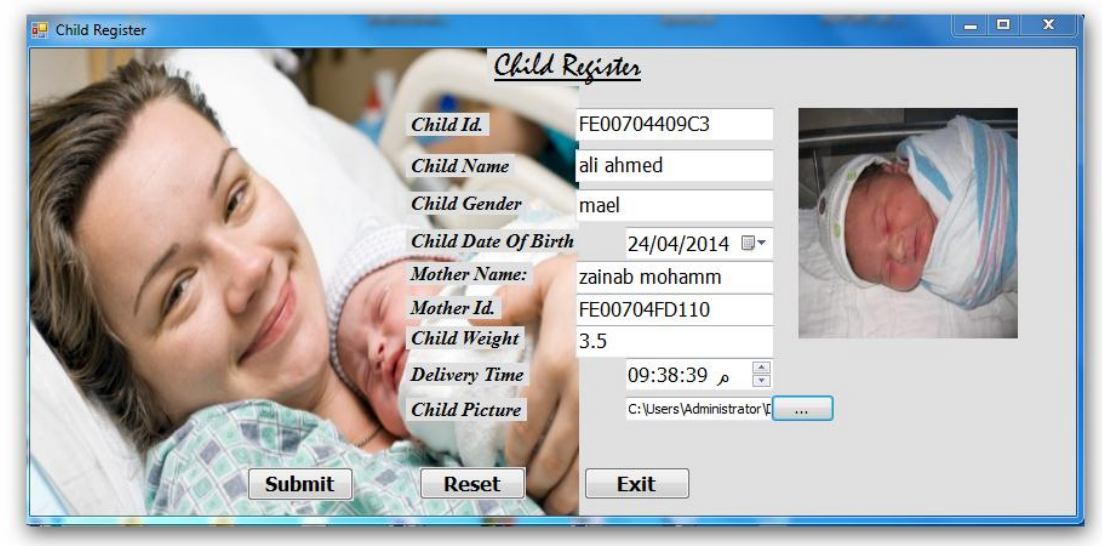

Figure 4: The child Information Registration interface

The mother Information will store in the system and the ID of tag will be for her ID, the child information will be stored in the system, the name and ID of his mother will be store in his record, the staff information will be stored in the system with the ID of tag.

RFID Reader is placed inside the newborn hall. This reader is used to read information of all tags inside that room. In case of loss of tag signal (that is verified automatically after one minute) the system will announces on the absence of that tag, alarm sound will be activated and the door of the hall will be locked(refer figure 5).

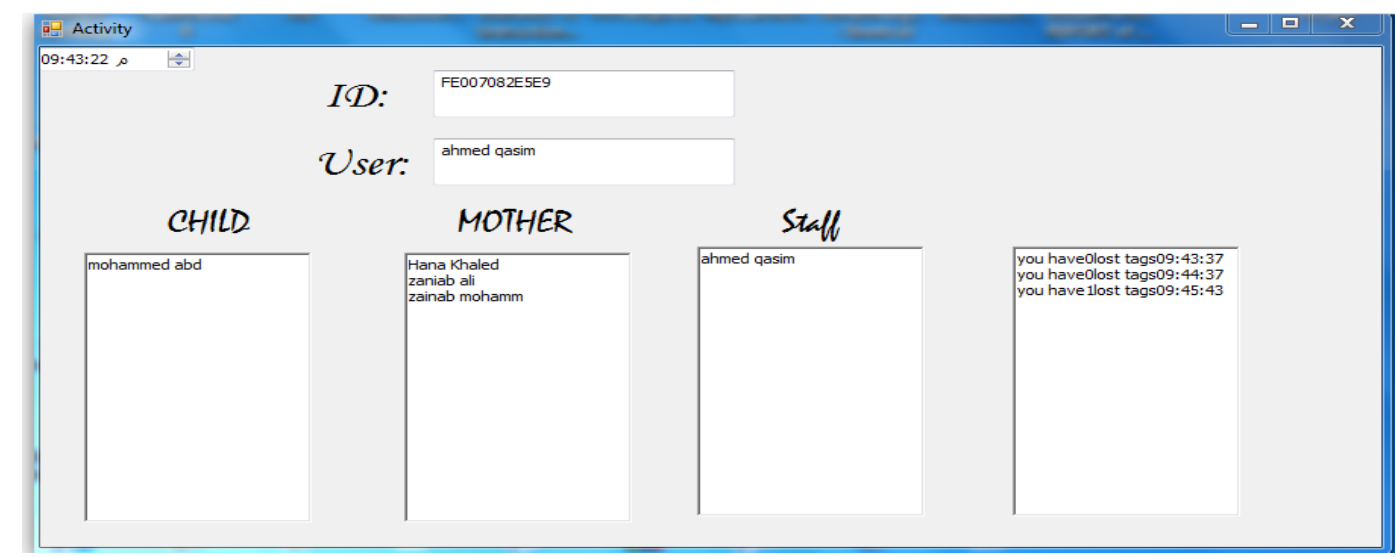

Figure 5: the activity interface

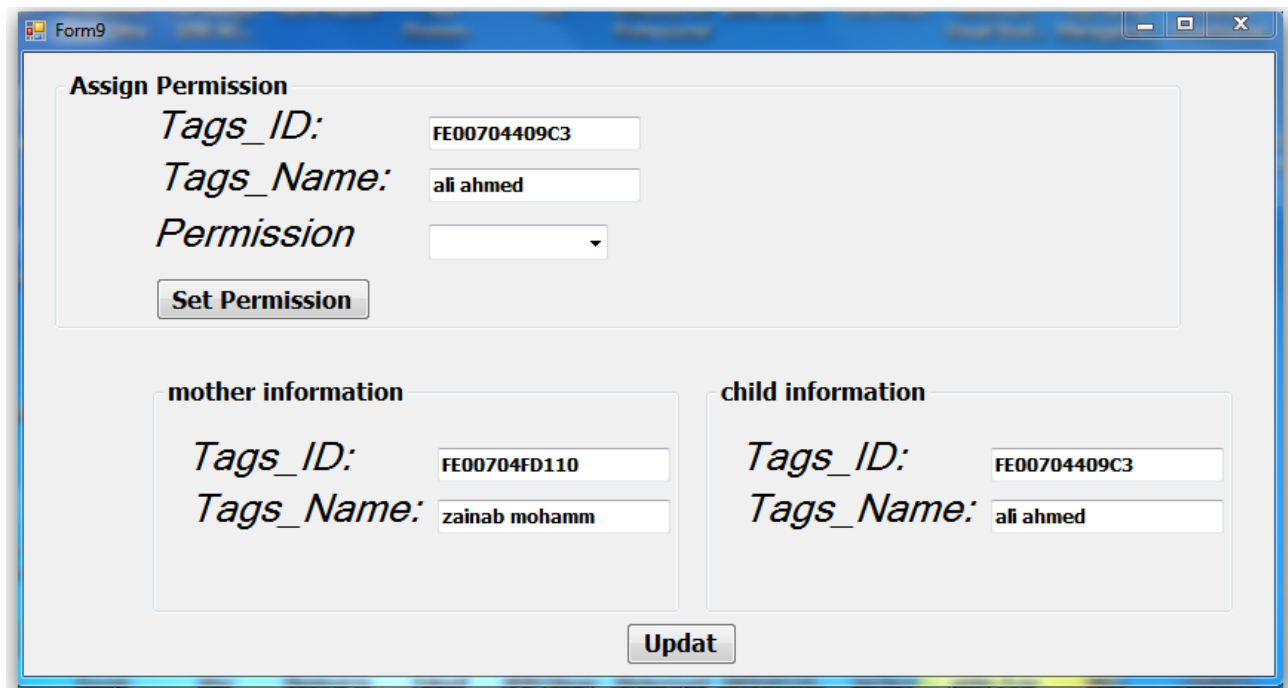

Figure 6: The Permission interface 
Permission of staff and mothers are adjusted through a system interface (refer figure 6) to increase the flexibility of the system. When a mother approaches with a child to the exit door, the system matches the mother's tag with child's tag and in the case of mismatch the door will not open and the alarms will be activated. In case the child needs to be shifted to another room, the system logs information that the nurse has transferred the child.

The wristband with RFID active tags shall be light weight, tamperproof and disposable in order to avoid biohazards. Any effort to remove or cut the wristband will trigger alarm if one is not authorized to do so. Even, any adjustment in the position of the baby is detected by the system.

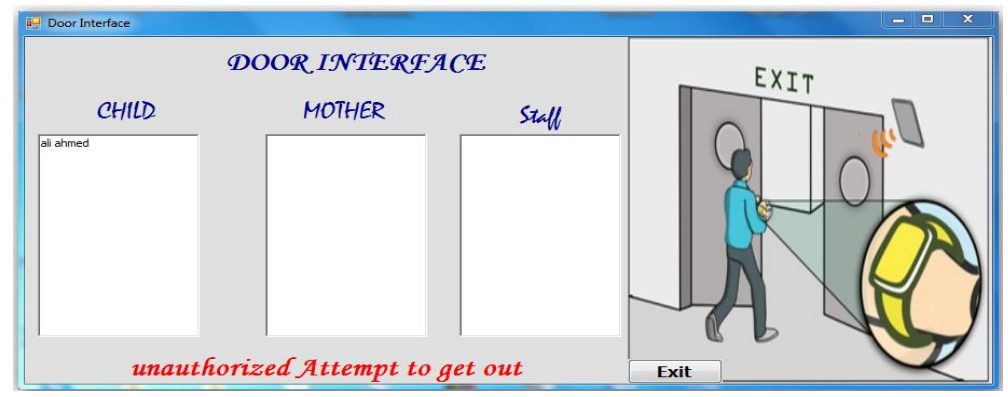

Figure 7: The Door Control interface

Exiting the ward is authenticated by the interface (refer figure 7) and if is not so an alarm will be activated for any such attempt. Even, such authorization is for limited duration; after the permitted time an alert will be automatically raised if the system doesn't detect the baby's tag in the ward.

\section{Implementation}

The major components that have been used by the system described above are:

1. Hardware: includes RFID reader, RFID tags, different terminals and necessary infrastructure.

2. Database: that is used to store persistent necessary information that has been normalized. These information than may be retrieved as per need. For this purpose SQL server 2008 has been used.

3. User interface: is the point of access of the system. For this purpose C\#. Net 2010 has been used.

There are a two of key hardware components that need some further explanations that are:

i. Active RFID Transmitter tag which transmits 16 bit unique ID on $433 \mathrm{MHz}$ frequency giving range of around 25 meters. It is powered by its Printed Circuit Board(PCB) mounted 3Volt battery at bottom. Total of 64 such active RFID transmitter tag can co-exist with each other in same premises each automatically occupying its own time slot without interfering with each other. The RFID receiver is used for listening to these tags.

ii. RFID reader that is connected to a computer by serial port . C\# is used to access the SerialPort object and to manage COM port connections. These elements are located inside the toolbox of the IDE where it can be dragged onto a form.

In order to open the serial port, the PortName, BaudRate, Handshake and StopBits properties are to be set. Once the connection properties have been set, the port can be opened using the Open()routine.

serialPort1.PortName $=$ lbComPort. Text ;

serialPort 1 BaudRate $=$ Convert.ToInt32 $($ tbBaudRate.Text $)$;

serialPort1.Handshake $=$ Handshake. None ;

serialPort1.StopBits $=$ StopBits. One ;

serialPort1.Open();

Code snippet 1.: Setting the properties PortName, BaudRate, Handshake and StopBits

The code snippet 1 is used to initialize PortName, BaudRate, Handshake and StopBits

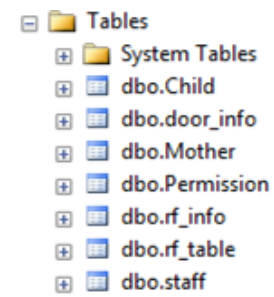

Figure 8: Tables used in the system 
The database of the candidate system (refer figure 8) uses seven tables. The brief description of these tables has been made available in table 1 for the reference.

\begin{tabular}{|c|l|l|}
\hline S. No. & Table Name & Description \\
\hline 1. & Child & To store children information with mother name and ID \\
\hline 2. & Mother & To store mothers information \\
\hline 3. & Staff & To store the staff information \\
\hline 4. & Permission & Determine the permission of each tag and used to know who has permission \\
\hline 5. & Rf_info & To store the activity information of each tag \\
\hline 6. & Rf_table & To store the information of Who take the tag(staff, child,mother) \\
\hline 7. & Door_info & To store the information of Time out of room \\
\hline
\end{tabular}

Table 1: Brief description of tables for persistent data

\section{Conclusion}

The present work is an attempt to explore and describe the basic architecture of newborn protection System using RFID technology. A set of two wristbands of RFID active tag with same ID is used for child and mother. These tags transmit their ID's the installed readers in regular interval of time. The candidate system then keep track of the ID's broadcasted by the tags and store necessary information into the database for the purpose of tracking the movements of children, mothers and staff members present in the hall. The above setup will stop any attempt of cradle kidnap and cradle exchange.

\section{REFERENCES}

[1] BlueBean, (2007), The Benefits of RFID in the Healthcare Organization, RFID Solutions for the Healthcare Industry, [Available:Online] URL: http://www.rfidhealthcare.com/ .

[2] Klaus Finkenzeller.(2010), RFID Handbook, Fundamentals and Applications in Contactless Smart Cards, Radio Frequency Identification and Near-Field Communication, 3rd Edition

[3] Shrikant Tiwari, Aruni Singh and Sanjay Kumar Singh,( 2013), Multimodal Database of Newborns for Biometric Recognition, International Journal of Bio-Science and Bio-Technology, Vol. 5, No. 2, April, 2013.

[4] J. E. Gray, G. Suresh, R. Ursprung, W. H. Edwards, J. Nickerson and P. H.Shinno, (2006), Patient Misidentification in the neonatal intensive care unit: Quantification of risk, Pediatrics, vol. 11, pp. 46-e47.

[5] A. K. Jain, A. Ross and S. Prabhakar, (2004), An introduction to biometric recognition, IEEE Trans. Circuits and Systems for Video Technology, vol. 14, no. 1, pp. 4-20.

[6] Garfinkel \&Rosenberg, eds , (2006), RFID Applications, Security, and Privacy. 2006

[7] Hunt VD, Puglia A, Puglia M,(2007), RFID - A Guide to Radio Frequency Identification, Wiley: New York, NY.

[8] V. Derbek, C. Steger, R. Wei, D. Wischounig, J. Preishuber-Pfluegl and M. Pistauer (2007), Simulation Platform for UHF RFID, DATE '07: Design, Automation and Test in Europe - Conference and Exhibition, Nice,France.

[9] Haley CK, Jacobsen LA, Robkin S., (2007), Radio Frequency Identification Handbook for Librarians, Greenwood Publishing Group, Inc.: Santa Barbara, CA.

[10] Radio Frequency Identification Fundamentals and Applications, Design Methods and Solutions, Book edited by: Cristina Turcu,ISBN 978-953-7619-72-5, pp. 324, February 2010, INTECH, Croatia, downloaded from SCIYO.COM. 